\title{
Study on Product Configuration Based on Preference of Consumer
}

\author{
Lanhua Zhou ${ }^{\mathrm{a}}$ Fuhong Zeng ${ }^{\mathrm{b}}$ \\ Panzhihua University, Panzhihua 617000, China \\ azhoulanhuazk@163.com, bengfuhong@163.com
}

\begin{abstract}
Keywords: Conjoint analysis, purchase preference of consumer, product configuration
Abstract. In order to increase market competition of enterprise products by blending Purchase Preference of Consumer (PPC) in product configuration design. A configuration model of product based on PPC was established, which effectively integrated Configuration Units (CU) and Configuration Rules(CR) and Configuration Constraints (CC) at the core with Generic Units(GU), The solution of analysis on PPC was presented based on conjoint analysis method, and an algorithm for solving consumer utility value of CU based on SPSS software was given. An algorithm system was designed for configuration scheme solving with objective of maximize PPC satisfaction. Finally, a configurable computer case was presented to verify the effectiveness and feasibility of the presented approach.
\end{abstract}

\section{Introduction}

The configuration of products is the process for obtaining the best in varies of product configuration programs by combining the different values of each domain which meet with pre-defined constraints and rules. Fast configuration design of product is the key technology to realize mass customization. To describe and solve the problem of product configuration, scholars at home and abroad did plenty of research and put forward some solving methods, where representative examples are Case-Based Reasoning(CBR)[1], Rule-Based Reasoning(RBR)[2], Artificial Intelligence(AI)[3], and Object Oriented(OO)[4] Bill of Material(BOM).

The solution of problems of product configuration is mainly based on constraint satisfaction. Under current demand-led market economy, Consumer preference is an important factor. There are few report on how to integrate consumer preference into product configuration design. In this paper, consumer preference product configuration model is defined first. In Section 2, The algorithm for configuration design of product is worked out by combining conjoint analysis technology with constraint solving technology. In Section3, the configurable computer case is selected as an example to verify the model $\&$ algorithm. Section 4 provides the concluding remarks.

\section{The definition for product Configuration model based on Consumer preference}

In fast design of product configuration, product configuration should have two basic features which are predefined configurable unit and Predefined Matching rules. In addition, a driving element and an result of Engineering BOM (EBOM) are essential. Product configuration model based on Consumer preference can be regard as (GU,GR,GC) . The Configuration model is shown in Fig.1.

1) GU is General Unit(GU), general unit is abstraction to the set of similar and optional configuration unit, the $\mathrm{i}$-th $\mathrm{GU}$ can be expressed as:

$\mathrm{GU}_{\mathrm{i}}=\left(\mathrm{GID}, \mathrm{GA}, \mathrm{GU}_{\mathrm{i}}(\mathrm{CU}), \mathrm{GT}, \mathrm{GUS}, \mathrm{GN}\right)$

(1) GID is the unique id of $\mathrm{GU}_{\mathrm{i}}$

(2) GA is properties set that include many basic properties

(3) $\mathrm{GUi}(\mathrm{CU})$ is set of $\mathrm{CU}$, which is expressed in $\mathrm{GU}_{\mathrm{i}}=\left\{\mathrm{CU}_{\mathrm{i} 1}, \mathrm{CU}_{\mathrm{i} 2}, \ldots, \mathrm{CU}_{\mathrm{in}}\right\}$

Configuration unit can be expressed as $\mathrm{CU}=(\mathrm{CUO}, \mathrm{CUS})$, where CUO is the Ontology of configuration unit and CUS is the set of related object. CUO is the formal specification of the configuration object, can be regard as $C U O=(C I D, C A, C C)$, where CID is the id of configuration unit, $\mathrm{RO}$ is properties set that include many basic properties and $\mathrm{CC}$ is set of configuration rules; CUS can be 
regard as $\mathrm{CUS}=(\mathrm{CID}, \mathrm{RO}), \mathrm{CID}$ is the id of configuration unit, $\mathrm{RO}$ is the set of related object.

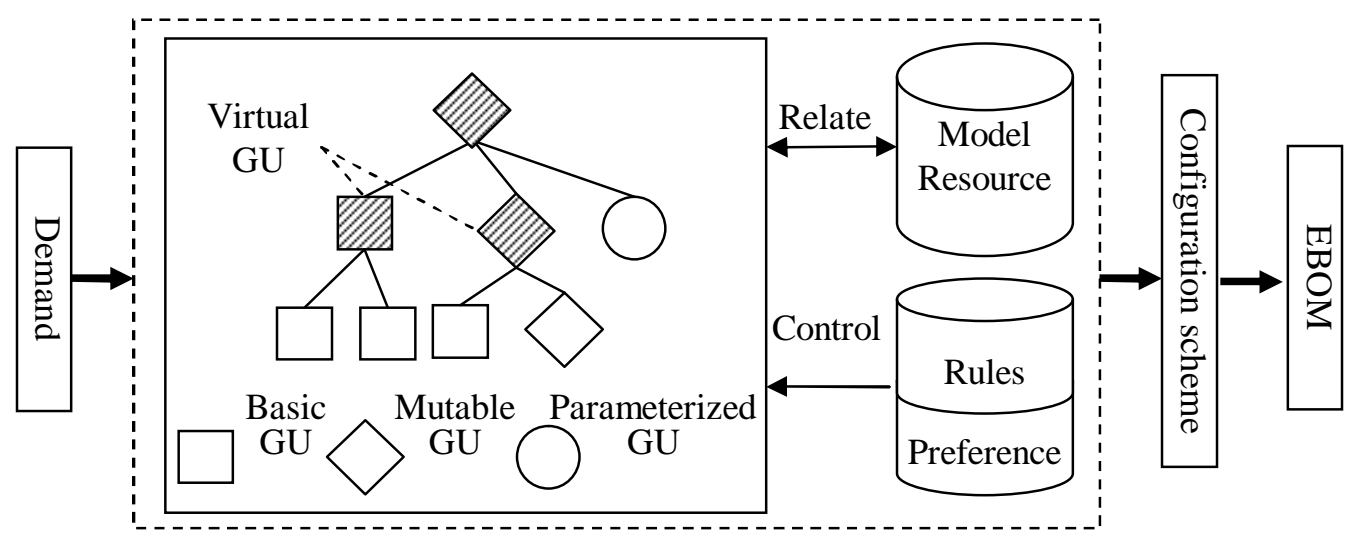

Fig1. The configuration model

(4) GT is denoted to express the type of GUi, which includes two types named Virtual General Unit(VGU) \& Instance General Unit(IGU). VGU has no CU in it, which is expressed in:

$\mathrm{GU}_{\mathrm{i}}(\mathrm{CU})=\{\mathrm{CU}$ : instance $(\mathrm{CU})\}$. IGU is express as $\left.\mathrm{GU}_{\mathrm{i}}(\mathrm{CU})\right)=\{\mathrm{CU}$ : instance $(\mathrm{CU})\}$ which has one or more CU.

(5) GUS is the style of GU which is determined by its optional configuration unit, can be divided into basic GU (GUS=1), mutable GU(GUS=2) and parameterized GU(GUS=3). The spare part of basic $\mathrm{GU}$ is essential for realizing the core of product, whose property value is fixed, can be selected directly. The spare part of mutable GU can change to be suitable for the configuration design. The parameterized GU can offer parametric description for its parent unit.

(6) GN is the number of configuration

2) GR is set of configuration rules for GU, include father-son relationship and brotherhood

3) GC is the matching rules, consumer-preference GC is defined in this title: In the situation of constraint satisfaction, the CU with large value will be selected after considering the importance of GU and related utility value of the $\mathrm{CU}$.

\section{Solution for the design of product configuration}

Consumer-preference solution for the design of product configuration can be regarded as a progress to search the best constraint-satisfaction configuration for consumer in all possible sets of configuration with configuration-require drive. It has two cores: determine the configuration unit, optimize and solve the configuration.

1) Compute the utility value of configuration unit

The utility value of $\mathrm{CU}$ is used to express the importance of ever CU, decompose the value of configuration unit into argument according to consumer's preference or evaluate to full-sized, use Ordinary Least Square(OLS) to get the regressions jointly estimate. The algorithm process is: configure virtual product $\rightarrow$ consumer survey $\rightarrow$ compute the utility value of configuration unit with conjoint analysis

(1)Configure virtual product

Because of the variety of optional configuration unit, nobody can do a survey about all the product combination, so use the means of orthogonal design to combine CU into series of virtual products. When the model of $\mathrm{CU}$ is too complicated(beyond 2 layers), it should be decomposed into small parts by virtual GU, then use the means of orthogonal design to combine those parts into series of virtual parts, and do survey by those virtual parts

(2) Consumer survey

According to the consumer for product, the sampling of investigation group is designed with simple and effective principles. To get proper feeling about consumer to each product combination, use 9 point for the Link table to do the survey about the possibility of people buy the virtual product. It is 
shown in Fig.2. People who give more marks have more possibility to buy. Interview is used to collect survey data

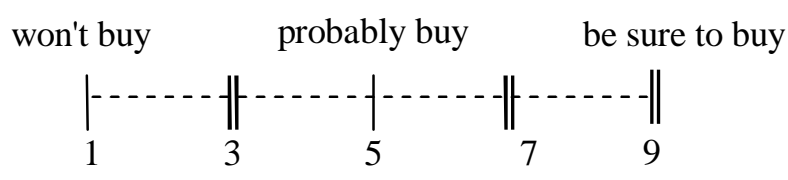

Fig2.9 point for the Link table.

(3)Determine the utility value of configuration unit with conjoint analysis

Based on the record above, conjoint analysis is used to decompose the utility value of $\mathrm{CU}$ by the means of mathematical statistics to get the evaluate about importance of each $\mathrm{CU}$, and then, get the utility value of consumer. This research use SPSS to complete conjoint analysis, at first, a syntax file is setup, and is shown in Fig.3, then the importance $\left(\mathrm{w}_{\mathrm{i}}\right)$ and utility value $\left(\mathrm{S}_{\mathrm{ij}}\right)$ of each GU will be gotten by running the file in SPSS. When the product is virtual secondary products, the $\mathrm{w}_{\mathrm{i}}$ should be computed by:

$$
w_{i}=w_{i}^{\prime} \times w_{i}^{f}
$$

Where, the $w_{i}$ is the importance of the $\mathrm{i}$-th unit gotten by disposing record of product, $w_{i}^{f}$ is the importance of i-th unit's parent unit.

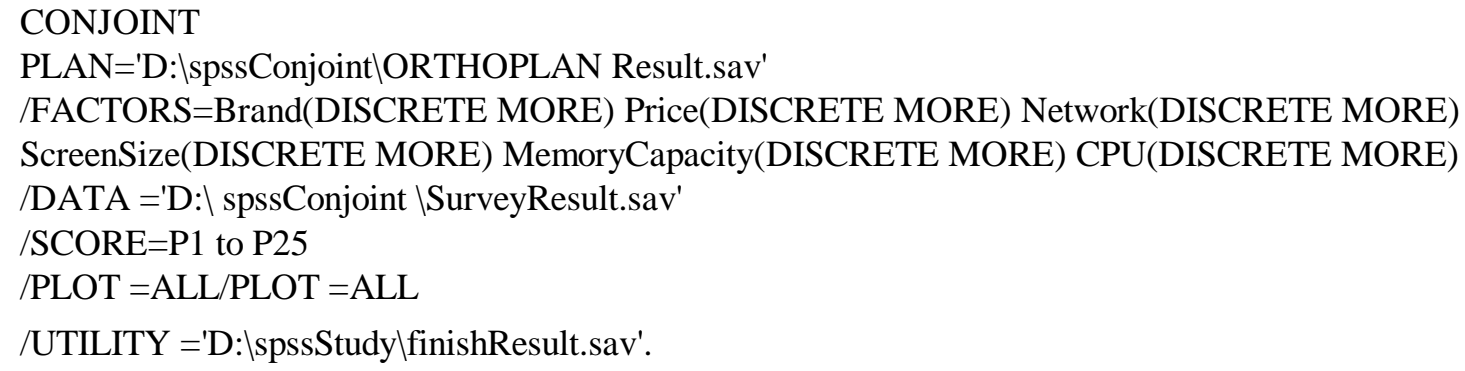

Fig3. Syntax file for conjoint analysis.

2) Solving the problem of configuration

Solving the problem of configuration is a progress witch combine CU in some ways with constraint satisfaction to get the best. The mathematics model about the fitness of the best scheme is presented as:

$$
\begin{cases}\max & f_{k}=\sum_{i=1}^{\text {chromlength }} w_{i} \times S_{i j} \\ \text { s.t. } & \mathrm{g}(\mathrm{x}) \leq 0\end{cases}
$$

Where, the $w_{i}$ is the importance of the $\mathrm{i}$-th $\mathrm{GU}, \mathrm{S}_{\mathrm{ij}}$ is the utility value of $\mathrm{i}$-th GU's $\mathrm{j}$-th CU, $\mathrm{g}(\mathrm{x})$ isconstraint function. $\mathrm{f}_{\mathrm{k}}$ is the fitness of configuration scheme

\section{Illustrative Example}

A computer company plan to introduce a series of learning and entertaining computer for undergraduate, whose allocation of resources is shown in table 1.

1) Configuring virtual product: Orthogonal experiment is used to combine virtual product by selecting CU in each GU, the result of orthogonal experiment is shown in table 2.

2) Interview: To get proper feeling of people about the product, Link table marking method(shown in Fig 2) is used to get the possibility about if people will buy the product. There are 179 effective samples; the result of the interview is shown in table 3. 
Table 1 Allocation of resources

\begin{tabular}{|c|c|c|c|c|c|}
\hline \multicolumn{2}{|r|}{$\begin{array}{c}\text { Monitor: } \mathrm{GID}=\mathrm{GU}_{1} \\
\mathrm{GT}=2, \quad \text { GUS }=2, \quad \mathrm{GN}=1\end{array}$} & \multicolumn{2}{|r|}{$\begin{array}{c}\text { CPU: } \quad \text { GID }=\text { GU2 } \\
\text { GT }=2, \quad \text { GUS }=2, \quad \text { GN }=1\end{array}$} & \multicolumn{2}{|r|}{$\begin{array}{c}\text { Memory: GID }=\text { GU3 } \\
\text { GT }=2, \text { GUS }=2, G N=1\end{array}$} \\
\hline$\overline{\mathrm{CID}}$ & Attribute of CU (CA) & CID & Attribute of CU (CA) & CID & Attribute of CU (CA) \\
\hline $\mathrm{CU}_{11}$ & Benq EW2440L ( ¥ 1290 & $\mathrm{CU}_{21}$ & AMD A10-7850K（ Y740） & \multicolumn{2}{|c|}{$\mathrm{CU}_{31}$ Vgan 4GB DDR3（ ¥ 135) } \\
\hline $\mathrm{CU}_{12}$ & HKC G2413L（ ¥ 1075） & $\mathrm{CU}_{22}$ & Intel Core i7 4765T ( ¥1180) & $\mathrm{CU}_{32}$ & Kingston 2GB DDR3 ( $¥ 78$ ) \\
\hline $\mathrm{CU}_{13}$ & $\begin{array}{l}\text { AOC U2870VQE } \\
(¥ 1310)\end{array}$ & $\mathrm{CU}_{23}$ & AMD FX-6300（ ¥680） & $\mathrm{CU}_{33}$ & Apacer 4GB DDR3 ( ¥132) \\
\hline $\mathrm{CU}_{14}$ & $\begin{array}{l}\text { AOC I2579V/WS } \\
(¥ 1175)\end{array}$ & $\mathrm{CU}_{24}$ & Intel Core i5-4590（ ¥750） & & \\
\hline $\mathrm{CU}_{15}$ & AOC I2369V（¥980） & $\mathrm{CU}_{25}$ & Intel Core i7 2700K ( ¥2080) & & \\
\hline \multicolumn{2}{|r|}{$\begin{array}{l}\text { HardDisk: } \mathrm{GID}=\mathrm{GU} 4 \\
\mathrm{GT}=2, \quad \mathrm{GUS}=2, \mathrm{GN}=1\end{array}$} & \multicolumn{2}{|r|}{$\begin{array}{c}\text { Graphics: GID= GU5 } \\
\text { GT }=2, \text { GUS }=2, \quad \text { GN }=1\end{array}$} & \multicolumn{2}{|r|}{$\begin{array}{l}\text { Motherboard: GID = GU6 } \\
\text { GT }=2, \text { GUS }=2, \quad \text { GN }=1\end{array}$} \\
\hline CID & Attribute of CU (CA) & CID & Attribute of CU (CA) & CID & Attribute of CU (CA) \\
\hline $\mathrm{CU}_{41}$ & Seagate 2TB ( $¥ 250)$ & $\mathrm{CU}_{51}$ & $\begin{array}{l}\text { ZOTAC GTX960-4GD5 } \\
(¥ 1590)\end{array}$ & $\mathrm{CU}_{61}$ & $\begin{array}{l}\text { GIGABYTE B85M-D3H } \\
(¥ 490)\end{array}$ \\
\hline $\mathrm{CU}_{42}$ & $\begin{array}{l}\text { Hitachi 7K1000.C2TB } \\
\text { ( ¥325) }\end{array}$ & $\mathrm{CU}_{52}$ & XFX R9 270 2G（ ¥ 899） & $\mathrm{CU}_{62}$ & $\begin{array}{l}\text { ASUS B 85-PRO GAMER } \\
\text { ( ¥699) }\end{array}$ \\
\hline \multirow[t]{3}{*}{$\mathrm{CU}_{43}$} & $\begin{array}{l}\text { Seagate Barracuda 2TB } \\
\text { ( ¥350) }\end{array}$ & $\mathrm{CU}_{53}$ & $\begin{array}{l}\text { ZOTAC GTX960-2GD5 } \\
\text { ( ¥1499) }\end{array}$ & $\mathrm{CU}_{63}$ & $\begin{array}{l}\text { GIGABYTE Z97X-UD3H } \\
\text { ( ¥799) }\end{array}$ \\
\hline & & $\mathrm{CU}_{54}$ & Lei FengHD7850（ ¥ 1099） & $\mathrm{CU}_{64}$ & $\begin{array}{l}\text { GIGABYTE B85-HD3 } \\
\text { ( ¥499) }\end{array}$ \\
\hline & & $\mathrm{CU}_{55}$ & $\begin{array}{l}\text { ZOTAC GTX660-2GD5 } \\
\text { ( ¥999) }\end{array}$ & & \\
\hline \multicolumn{6}{|c|}{ GC: $\quad\left(C U_{32} \wedge \neg C U_{62}\right) \vee\left(C U_{62} \wedge \neg C U_{32}\right)$} \\
\hline
\end{tabular}

Table 2. The result of orthogonal experiment

\begin{tabular}{|c|c|c|c|c|c|}
\hline No & Configuration scheme & No & Configuration scheme & No & Configuration scheme \\
\hline P1 & $\begin{array}{c}\mathrm{CU}_{12}, \mathrm{CU}_{22}, \mathrm{CU}_{32}, \mathrm{CU}_{42}, \mathrm{CU}_{51} \\
\mathrm{CU}_{61}\end{array}$ & P10 & $\begin{array}{c}\mathrm{CU}_{13}, \mathrm{CU}_{22}, \mathrm{CU}_{31}, \mathrm{CU}_{41}, \mathrm{CU}_{52} \\
\mathrm{CU}_{62}\end{array}$ & P19 & $\begin{array}{c}\mathrm{CU}_{15}, \mathrm{CU}_{23}, \mathrm{CU}_{33}, \mathrm{CU}_{41}, \mathrm{CU}_{53}, \\
\mathrm{CU}_{63}\end{array}$ \\
\hline $\mathrm{P} 2$ & $\begin{array}{c}\mathrm{CU}_{11}, \mathrm{CU}_{25}, \mathrm{CU}_{31}, \mathrm{CU}_{41}, \mathrm{CU}_{54}, \\
\mathrm{CU}_{63}\end{array}$ & P11 & $\begin{array}{c}\mathrm{CU}_{14}, \mathrm{CU}_{21}, \mathrm{CU}_{32}, \mathrm{CU}_{42}, \mathrm{CU}_{52} \\
\mathrm{CU}_{63}\end{array}$ & $\mathrm{P} 20$ & $\begin{array}{c}\mathrm{CU}_{12}, \mathrm{CU}_{21}, \mathrm{CU}_{31}, \mathrm{CU}_{43}, \mathrm{CU}_{53}, \\
\mathrm{CU}_{61}\end{array}$ \\
\hline P3 & $\begin{array}{c}\mathrm{CU}_{14}, \mathrm{CU}_{22}, \mathrm{CU}_{33}, \mathrm{CU}_{43}, \mathrm{CU}_{54}, \\
\mathrm{CU}_{61}\end{array}$ & P12 & $\begin{array}{c}\mathrm{CU}_{13}, \mathrm{CU}_{23}, \mathrm{CU}_{32}, \mathrm{CU}_{42}, \mathrm{CU}_{54}, \\
\mathrm{CU}_{61}\end{array}$ & $\mathrm{P} 21$ & $\begin{array}{c}\mathrm{CU}_{13}, \mathrm{CU}_{25}, \mathrm{CU}_{32}, \mathrm{CU}_{41}, \mathrm{CU}_{53}, \\
\mathrm{CU}_{61}\end{array}$ \\
\hline $\mathrm{P} 4$ & $\begin{array}{c}\mathrm{CU}_{13}, \mathrm{CU}_{23}, \mathrm{CU}_{32}, \mathrm{CU}_{43}, \mathrm{CU}_{51}, \\
\mathrm{CU}_{63}\end{array}$ & P13 & $\begin{array}{c}\mathrm{CU}_{13}, \mathrm{CU}_{23}, \mathrm{CU}_{31}, \mathrm{CU}_{41}, \mathrm{CU}_{51}, \\
\mathrm{CU}_{64}\end{array}$ & $\mathrm{P} 22$ & $\begin{array}{c}\mathrm{CU}_{12}, \mathrm{CU}_{22}, \mathrm{CU}_{32}, \mathrm{CU}_{41}, \mathrm{CU}_{55}, \\
\mathrm{CU}_{63}\end{array}$ \\
\hline P5 & $\begin{array}{c}\mathrm{CU}_{11}, \mathrm{CU}_{22}, \mathrm{CU}_{32}, \mathrm{CU}_{42}, \mathrm{CU}_{53}, \\
\mathrm{CU}_{64}\end{array}$ & P14 & $\begin{array}{c}\mathrm{CU}_{12}, \mathrm{CU}_{24}, \mathrm{CU}_{32}, \mathrm{CU}_{41}, \mathrm{CU}_{54}, \\
\mathrm{CU}_{64}\end{array}$ & P23 & $\begin{array}{c}\mathrm{CU}_{12}, \mathrm{CU}_{25}, \mathrm{CU}_{33}, \mathrm{CU}_{42}, \mathrm{CU}_{51}, \\
\mathrm{CU}_{62}\end{array}$ \\
\hline P6 & $\begin{array}{c}\mathrm{CU}_{11}, \mathrm{CU}_{23}, \mathrm{CU}_{32}, \mathrm{CU}_{43}, \mathrm{CU}_{55} \\
\mathrm{CU}_{62}\end{array}$ & P15 & $\begin{array}{c}\mathrm{CU}_{15}, \mathrm{CU}_{22}, \mathrm{CU}_{32}, \mathrm{CU}_{41}, \mathrm{CU}_{51}, \\
\mathrm{CU}_{61}\end{array}$ & $\mathrm{P} 24$ & $\begin{array}{c}\mathrm{CU}_{15}, \mathrm{CU}_{21}, \mathrm{CU}_{32}, \mathrm{CU}_{41}, \mathrm{CU}_{54}, \\
\mathrm{CU}_{62}\end{array}$ \\
\hline P7 & $\begin{array}{c}\mathrm{CU}_{15}, \mathrm{CU}_{24}, \mathrm{CU}_{31}, \mathrm{CU}_{42}, \mathrm{CU}_{54}, \\
\mathrm{CU}_{61}\end{array}$ & P16 & $\begin{array}{c}\mathrm{CU}_{13}, \mathrm{CU}_{21}, \mathrm{CU}_{33}, \mathrm{CU}_{41}, \mathrm{CU}_{55}, \\
\mathrm{CU}_{64}\end{array}$ & $\mathrm{P} 25$ & $\begin{array}{c}\mathrm{CU}_{14}, \mathrm{CU}_{25}, \mathrm{CU}_{32}, \mathrm{CU}_{41}, \mathrm{CU}_{55}, \\
\mathrm{CU}_{61}\end{array}$ \\
\hline P8 & $\begin{array}{r}\mathrm{CU}_{11}, \mathrm{CU}_{21}, \mathrm{CU} \\
\mathrm{CU}\end{array}$ & P17 & $\begin{array}{c}\mathrm{CU}_{15}, \mathrm{CU}_{25}, \mathrm{CU}_{32}, \mathrm{CU}_{43}, \mathrm{CU}_{52}, \\
\mathrm{CU}_{64}\end{array}$ & & \\
\hline P9 & $\begin{array}{c}\mathrm{CU}_{11}, \mathrm{CU}_{24}, \mathrm{CU}_{33}, \mathrm{CU}_{41}, \mathrm{CU}_{52} \\
\mathrm{CU}_{61}\end{array}$ & P18 & $\begin{array}{c}\mathrm{CU}_{14}, \mathrm{CU}_{24}, \mathrm{CU}_{32}, \mathrm{CU}_{41}, \mathrm{CU}_{53}, \\
\mathrm{CU}_{62}\end{array}$ & & \\
\hline
\end{tabular}


Table 3. The result of the interview

\begin{tabular}{ccccccccccccccccccccccccccc}
\hline No & P1 & P2 & P3 & P4 P5 P6 P7 P8 P9 P10 P11 P12 P13 P14 P15 P16 P17 P18 P19 P20 P21 P22 P23 P24 P25 \\
\hline 1 & 3 & 3 & 3 & 7 & 7 & 6 & 2 & 7 & 7 & 7 & 5 & 7 & 3 & 3 & 3 & 7 & 3 & 5 & 3 & 5 & 7 & 6 & 7 & 3 & 5 \\
2 & 1 & 7 & 3 & 6 & 6 & 1 & 1 & 1 & 1 & 4 & 1 & 1 & 1 & 1 & 1 & 1 & 5 & 1 & 1 & 1 & 4 & 6 & 7 & 1 & 5 \\
3 & 1 & 5 & 4 & 1 & 1 & 1 & 1 & 1 & 1 & 1 & 1 & 1 & 1 & 1 & 1 & 1 & 4 & 1 & 1 & 1 & 5 & 2 & 5 & 1 & 1 \\
4 & 3 & 6 & 4 & 4 & 8 & 5 & 4 & 7 & 5 & 5 & 3 & 4 & 2 & 4 & 5 & 3 & 7 & 4 & 3 & 6 & 7 & 8 & 9 & 5 & 6 \\
5 & 3 & 8 & 5 & 4 & 7 & 5 & 3 & 5 & 5 & 4 & 4 & 3 & 3 & 5 & 5 & 3 & 5 & 4 & 2 & 3 & 6 & 7 & 8 & 3 & 7 \\
6 & 1 & 9 & 1 & 6 & 7 & 5 & 1 & 1 & 1 & 8 & 5 & 1 & 2 & 5 & 1 & 5 & 8 & 5 & 3 & 2 & 4 & 6 & 8 & 5 & 1 \\
7 & 1 & 6 & 6 & 8 & 6 & 1 & 1 & 1 & 1 & 6 & 4 & 4 & 2 & 1 & 1 & 2 & 1 & 2 & 1 & 1 & 5 & 1 & 1 & 1 & 3 \\
8 & 1 & 8 & 1 & 6 & 6 & 7 & 1 & 2 & 1 & 7 & 6 & 1 & 5 & 4 & 1 & 6 & 5 & 6 & 5 & 1 & 2 & 5 & 6 & 5 & 1 \\
9 & 2 & 3 & 5 & 4 & 6 & 6 & 5 & 4 & 3 & 2 & 2 & 2 & 1 & 1 & 1 & 2 & 2 & 3 & 2 & 1 & 2 & 3 & 2 & 2 & 3 \\
& & & & & & & & & & & & $\circ$ & $\circ$ & $\circ$ & $\circ$ & $\circ$ & & & & & & & & & & \\
178 & 7 & 4 & 2 & 6 & 6 & 8 & 1 & 8 & 8 & 6 & 1 & 8 & 1 & 7 & 1 & 8 & 1 & 1 & 1 & 8 & 3 & 6 & 5 & 1 & 1 \\
179 & 2 & 8 & 2 & 5 & 6 & 4 & 2 & 7 & 7 & 8 & 4 & 5 & 4 & 4 & 4 & 5 & 4 & 2 & 3 & 3 & 7 & 3 & 2 & 3 & 3 \\
\hline
\end{tabular}

3) Computing the utility value of CU: conjoint analysis program files(shown in Fig 3) are called to get the result(shown in table 4) by SPSS.

4) Solving the problem of configuration: The configuration result gotten by the mathematic about the fitness is: when budget is lower than $4000 ¥, \mathrm{CU13} 、 \mathrm{CU} 24 、 \mathrm{CU} 31 、 \mathrm{CU} 43 、 \mathrm{CU} 52 、 \mathrm{CU} 64$ are used as configuration scheme, the fitness value of which is 0.2750 , price is $3943 ¥$.When budget is lower than $4200 ¥$, the configuration scheme change to be CU13,CU24,CU32,CU43,CU52,CU63. EBOM can be determined by arranging those configuration schemes.

Table 4.Result of conjoint analysis

\begin{tabular}{|c|c|c|c|c|c|c|c|c|}
\hline \multicolumn{3}{|c|}{ Monitor $\left(\mathrm{GU}_{1}\right)$} & \multicolumn{3}{|c|}{$\mathrm{CPU}\left(\mathrm{GU}_{2}\right)$} & \multicolumn{3}{|c|}{$\operatorname{Memory}\left(\mathrm{GU}_{3}\right)$} \\
\hline CID & $\begin{array}{l}\text { the utility } \\
\text { value }\left(S_{i j}\right)\end{array}$ & $\begin{array}{c}\text { importance } \\
\left(w_{i}\right)\end{array}$ & CID & $\begin{array}{l}\text { the utility } \\
\text { value }\left(S_{i j}\right)\end{array}$ & $\begin{array}{c}\text { importance } \\
\left(w_{i}\right)\end{array}$ & CID & $\begin{array}{l}\text { the utility } \\
\text { value }\left(S_{i j}\right)\end{array}$ & $\begin{array}{c}\text { importance } \\
\left(w_{i}\right)\end{array}$ \\
\hline $\mathrm{CU}_{11}$ & 0.652 & \multirow{5}{*}{$31.718 \%$} & $\mathrm{CU}_{21}$ & -0.364 & \multirow{5}{*}{$34.015 \%$} & $\mathrm{CU}_{31}$ & 0.087 & \multirow{5}{*}{$2.540 \%$} \\
\hline $\mathrm{CU}_{12}$ & -0.574 & & $\mathrm{CU}_{22}$ & 0.553 & & $\mathrm{CU}_{32}$ & -0.073 & \\
\hline $\mathrm{CU}_{13}$ & 1.100 & & $\overline{\mathrm{CU}_{23}}$ & -1.097 & & $\mathrm{CU}_{33}$ & -0.014 & \\
\hline $\mathrm{CU}_{14}$ & -0.277 & & $\mathrm{CU}_{24}$ & -0.141 & & & & \\
\hline $\mathrm{CU}_{15}$ & -0.900 & & $\mathrm{CU}_{25}$ & 1.048 & & & & \\
\hline \multicolumn{3}{|c|}{$\operatorname{HardDisk}\left(\mathrm{GU}_{4}\right)$} & \multicolumn{3}{|c|}{ Graphics $\left(\mathrm{GU}_{5}\right)$} & \multicolumn{3}{|c|}{ Motherboard $\left(\mathrm{GU}_{6}\right)$} \\
\hline CID & $\begin{array}{l}\text { the utility } \\
\text { value }\left(S_{i j}\right)\end{array}$ & $\begin{array}{c}\text { importance } \\
\left(w_{i}\right)\end{array}$ & CID & $\begin{array}{l}\text { the utility } \\
\text { value }\left(S_{i j}\right)\end{array}$ & $\begin{array}{c}\text { importance } \\
\left(w_{i}\right)\end{array}$ & CID & $\begin{array}{l}\text { the utility } \\
\text { value }\left(S_{i j}\right)\end{array}$ & $\begin{array}{c}\text { importance } \\
\left(w_{i}\right)\end{array}$ \\
\hline$\overline{\mathrm{CU}_{41}}$ & -0.180 & \multirow{5}{*}{$6.446 \%$} & $\mathrm{CU}_{51}$ & 0.257 & \multirow{5}{*}{$9.394 \%$} & $\mathrm{CU}_{61}$ & -0.558 & \multirow{5}{*}{$15.887 \%$} \\
\hline $\mathrm{CU}_{42}$ & -0.047 & & $\mathrm{CU}_{52}$ & -0.335 & & $\mathrm{CU}_{62}$ & 0.185 & \\
\hline $\mathrm{CU}_{43}$ & 0.227 & & $\mathrm{CU}_{53}$ & 0.200 & & $\mathrm{CU}_{63}$ & 0.444 & \\
\hline & & & $\mathrm{CU}_{54}$ & 0.039 & & $\mathrm{CU}_{64}$ & -0.071 & \\
\hline & & & $\mathrm{CU}_{55}$ & -0.162 & & & & \\
\hline
\end{tabular}

\section{Conclusion}

Integrating consumers' preference into the design of product configuration can ensure the developed product have a better market value and capture the market in time. To achieve the goal, a consumer-preference product configuration model is set up, where CU, configuration rules and configuration constraint are integrated effectively with GU as the core. Virtual product is set up based on this model, and then, the consumer preference is obtained by interviewing, the utility value of CU and the importance of GU can be determined by consumer preference with the conjoint analysis method. The Algorithm which is used to select the better CU is designed according to the utility value of $\mathrm{CU}$ and the importance of GU. The product developed with the idea above have much more competitive in the market. 


\section{Reference}

[1] Hwai-En Tsenga, Expert Systems with Applications, Vol29(2009),p.913-925.

[2] BRU GNACH M, Ecological Modelling,Vol160(2003),p.63-76.

[3] Yeh JY, WuTH, Chang JM, The International Journal of Advanced Manufacturing Technology. Vol31(2007);p.1233-1242.

[4] Dong Yang, Rui Miao, Hongwei Wu, Yiting Zhou, Expert Systems with Applications. Vol26(2009),p.4399-4411. 